NASA/TM-1999-209043

$\mathrm{N}=\mathrm{2}$

Novel Three-Dimensional Vertical Interconnect Technology for Microwave and

RF Applications

Kavita Goverdhanam

University of Michigan, Ann Arbor, Michigan

Rainee N. Simons

Dynacs, Inc., Brook Park, Ohio

Linda P.B. Katehi

University of Michigan, Ann Arbor, Michigan

Prepared for the

MTT-S International Microwave Symposium

sponsored by the Institute of Electrical and Electronics Engineers

Anaheim, California, June 13-19, 1999

National Aeronautics and

Space Administration

Glenn Research Center 


\section{Acknowledgments}

The authors are grateful to ONR (N00014-95-1-0546) for its support.

Available from

NASA Center for Aerospace Information 7121 Standard Drive

Hanover, MD 21076

Price Code: A02
National Technical Information Service 5285 Port Royal Road Springfield, VA 22100 Price Code: A02 


\title{
NOVEL THREE-DIMENSIONAL VERTICAL INTERCONNECT TECHNOLOGY FOR MICROWAVE AND RF APPLICATIONS
}

\author{
Kavita Goverdhanam', Rainee N. Simons ${ }^{2}$, and Linda P.B. Katehi' \\ 'Radiation Laboratory, EECS Department, University of Michigan, \\ Ann Arbor, Michigan 48109-2122 \\ ${ }^{2}$ NASA, Glenn Research Center, Dynacs Group, Cleveland, Ohio 441.35
}

\begin{abstract}
In this paper, novel 3D interconnects suitable for applications in microwave and RF integrated circuit technology have been presented. The interconnect fabrication process and design details are presented. In addition, measured and numerically modeled results of the performance of the interconnects have been shown. The results indicate that the proposed technology has tremendous potential applications in integrated circuit technology.
\end{abstract}

\section{INTRODUCTION}

Recently, Microwave and RF integrated circuits (ICs) based on Silicon/Silicon germanium device technology have emerged as a viable alternative to ICs based on III-V semiconductor device technologies for wireless applications. These applications have experienced an exponential growth during the past few years. Current state-of-the-art digital ICs are also based on silicon technology and have the potential to be mono-lithically integrated with the above analogue ICs. Therefore, it is apparent that future generation of silicon analog circuits would have integrated digital control functions to enable them to make intelligent decisions. These advanced silicon mixed signal ICs would require efficient interconnects to allow combining different transmission media, such as, Coplanar Stripline (CPS) and Coplanar Waveguide (CPW) for maximum design flexibility. In addition, they are useful for enhancing packing density in the vertical direction as in small hand held communication devices. The interconnects have to be small in size for low parasitic coupling capacitances, and simple to fabricate for high yield and low manufacturing cost.

In this paper, we present several new design concepts for three-dimensional (3D) interconnects on a high resistivity (HR) silicon $\left(\varepsilon_{\mathrm{r} 2}=11.7\right)$ wafer. The 3D interconnects constitute very small sections of CPS at two levels connected by metallized vias and separated by a thin layer of spin-on-glass (SOG). CPS has the advantages of eliminating backside processing due to it's uniplanar construction, and greatly simplifying vertical integration by the use of metallized vias. In addition, CPS being a slot type of transmission line allows easy integration of other transmission media, such as, slotline, CPW with finite width ground planes and micro-CPS [1] for greater design flexibility. The SOG has the advantage of low dielectric constant $\left(\varepsilon_{\mathrm{rl}}=3.1\right)$ and hence low parasitic coupling capacitance. In addition, the SOG also planarizes the circuit and this facilitates vertical integration [1]. The HR silicon wafer $(\rho>3000 \Omega-\mathrm{cm})$ has the advantage of lowering the signal attenuation in addition to improving the isolation hetween adjacent circuits.

In the following sections, first, the fabrication process of vertical interconnects is presented. Next, design considerations for the CPS vertical interconnects treated here are presented. The interconnects that are presented here are: CPS vertically interconnected overpass with a crossover. a CPS vertical interconnect with $180^{\circ}$ phase shift and a CPW vertical interconnect with $180^{\circ}$ phase shift. Last, in the section on results and discussion, first, the measured loss for CPS lines on HR Silicon is presented. Second, the computed results showing the performance of the CPS vertically interconnected overpass with a crossover is presented. The Finite Difference Time Domain (FDTD) [2] technique has been used to compute the performance of the CPS vertically interconnected overpass with a crossover. Finally, the measured phase characteristics of the CPS and CPW interconnects with $180^{\circ}$ phase shift are presented. The experimental work for the purpose of demonstrating the low loss feature of the interconnects was performed using $\mathrm{RT} /$ duroid. The fabrication and characterization of interconnects with SOG-on-HR silicon are currently in progress. It is interesting to note that the measured and FDTD simulated results indicate that the interconnects presented here exhibit very good performance over a broad range of frequencies.

\section{INTERCONNECT FABRICATION}

To begin the fabrication process. the lower strip conductor of thickness $t_{1}=0.8 \mu \mathrm{m}$ is fabricated on the HR Silicon substrate by a lift-off process [3]. Next, the dielectric spacer layer is built-up to the required thickness by multiple spin-coats. Accuglass $512 \mathrm{SOG}[4]$ is used as the dielectric spacer layer. The thickness $h_{1}$ of the Accuglass 512 SOG used here is $2.0 \mu \mathrm{m}$. Lastly, the upper strip conductor of thickness $t_{2}=2.0 \mu \mathrm{m}$ is fabricated using the liftoff process once again. Gold metallization is used for the conductors.

\section{DESIGN CONSIDERATIONS}

(a) CPS vertically interconnected overpass with crossover: A CPS vertically interconnected overpass with a crossover on a HR silicon wafer of thickness $h_{2}=400 \mu \mathrm{m}$ is 
shown in Figure 1. In this interconnect, the CPS strip width $W_{1}=W_{2}=W$ and the separations $S_{1}=S_{2}=S$ are chosen such that the characteristics impedance $Z_{\text {(Ps) }}$ is $50 \Omega$. The thickness of the SOG layer is $h$. The vertical interconnection between the first and the second level CPS conductors are provided by a pair of circular metallized vias. Each via in a pair is symmetrically located on the strip conductor and has a diameter $d$. A via pair is design as a small section of a vertical balanced transmission line with characteristic impedance $Z_{\text {raviat }}=50 \Omega$. The $Z_{\text {rnvial }}$ is related to the diameter $d$, separation betBeen vias in a pair $S_{4}$ and the dielectric constant of the medium surrounding the via $\varepsilon_{\mathrm{r} 1}$ through the expression, $Z_{\text {avia }}=\left(60 / \operatorname{sqrt}\left(\varepsilon_{\mathrm{r} 1}\right)\right) \cosh ^{-1}(N)$, where $N=0.5\left[\left(2 S_{4} / d\right)^{2}-2\right]$. The probe pad at the input and output for the characterization with microwave wafer probes is typically about $100 \mu \mathrm{m} \times 100 \mu \mathrm{m}$ in size.

(b) CPS Vertical Interconnect with $180^{\circ}$ phase shift:

A CPS $180^{\circ}$ phase shifter with vertically interconnected twisted overpass is shown in Figure 2. In this phase shifter, the CPS strip width $W$ and separation $S$ are chosen such that the characteristic impedance $Z_{\text {in(P) })}$ is $50 \Omega$. The via diameter $d$ is chosen to be the same as in Figure 1.

(c) CPW Vertical Interconnect with $180^{\circ}$ phase shift:

A CPW $180^{\circ}$ Phase shifter with vertically interconnected U-shaped overpass is shown in Figure 3. In this phase shifter, the CPW center strip conductor and slot widths $S$ and $W$ are chosen such that the characteristic impedance $Z_{\text {(x }(P)}$ is $50 \Omega$. The via diameter is chosen to be the same as in Figure 1.

\section{RESULTS AND DISCUSSION}

(a) Measured Loss of CPS on HR Silicon:

In order to estimate the efficiency of the interconnects,

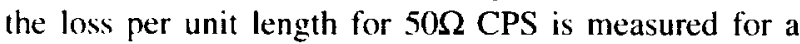
range of CPS test structures with $W$ ranging from 26 to $133 \mu \mathrm{m}$ and $S$ ranging from 2 to $10 \mu \mathrm{m}$. This range presents typical dimensions encountered in practical circuits. In Figure 4. the measured loss is presented as a function of $W$ and frequency. As an example, for a CPS with $W=54 \mu \mathrm{m}$ and $S=4 \mu \mathrm{m}$, the meas-ured loss is of the order of $0.46 \mathrm{~dB} / \mathrm{mm}$. The CPS crossover in Figure 1 has a length of about $328 \mu \mathrm{m}$ between the via pairs and hence the loss is estimated to be about $0.15 \mathrm{~dB}$ at $20 \mathrm{GHz}$. However, instead of choosing such small dimension, if $S$ is chosen to be larger, say $10 \mu \mathrm{m}$, the corresponding loss for a $50 \Omega$ line reduces to about $0.25 \mathrm{~dB} / \mathrm{mm}$, roughly reducing the total loss of the CPS crossover to about $0.075 \mathrm{~dB}$ at $20 \mathrm{GHz}$.

(b) CPS vertically interconnected overpass with crossover:

In order to study the performance of this interconnect, the scattering parameters ( $S$-parameters) were computed using the FDTD scheme and they are shown in Figure 5.
The computed S-parameters for the overpass alone indicate that the insertion loss, $\left(\mathrm{S}_{21}\right)$ is negligible and that the return loss $\left(\mathrm{S}_{11}\right)$ is about $-28 \mathrm{~dB}$. The computed $\mathrm{S}$-parameters for the overpass with a crossover shows that the insertion loss is still very small. However, $S_{11}$ has increased from $-28 \mathrm{~dB}$ to $-12 \mathrm{~dB}$. This increase in $S_{11}$ can be offset by providing a step compensation as shown in Figure 1. Simulations with the step compensation are in progress. Computed $S_{31}$ shows that the coupling between the overpass and the crossover is less than $-40 \mathrm{~dB}$.

(c) CPS and CPW vertical interconnects with $180^{\circ}$ Phase Shift:

The measured phase characteristics for these circuits are shown in Figures 6 and 7. In these figures, the phase shift of the interconnect is compared with the phase of an equivalent length of through-line. From the figures, it is observed that the phase shift of the interconnect is close to $180^{\circ}$ over a very broad range of frequencies. The excess loss of the interconnect is close to $0.1 \mathrm{~dB}$. FDTD simulations of the phase shifters are in progress.

\section{CONCLUSION}

A new 3D interconnect technology suitable for applications in microwave and RF integrated circuits has been proposed. Small sections of Coplanar Striplines connected by metallized vias and separated by a thin layer of spinon-glass have been used to realize a variety of broadband high performance circuits. This technology yields small sized interconnects which are simple to fabricate. As examples, the CPS vertically interconnected overpass with a crossover, and $180^{\circ} \mathrm{CPS}$ and CPW phase shifters have been presented. The results obtained indicate the suitability of the proposed approach in facilitating 3D integration.

\section{REFERENCES}

1. K. Goverdhanam, R.N. Simons and L.P.B. Katehi, "Micro-Coplanar Striplines-new transmission Media for Microwave Applications," 1998 IEEE MTT-S Inter. Microwave Symp., Dig., Vol. 2, Baltimore, Maryland, pp. 1035-1038, 1998.

2. K. Goverdhanam, R.N. Simons and L.P.B. Katehi, "Coplanar Stripline Components for High-Frequency Applications," IEEE Trans. on Microwave Theory and Techniques, Vol. 45, No. 10, pp. 1725-1729. Oct. 1997.

3. R. Williams, "Modern GaAs processing Methods," 2nd ed., Ch. 6, Norwood, MA: Artech House Inc. 1990.

4. Accuglass A $^{(1)} 512$ Spin-on-Glass (SOG), Product Bulletin, Allied-Signal Inc., Planarization and diffusion products, $1090 \mathrm{~S}$. Milpitas Blvd., Milpitas CA 95035. 


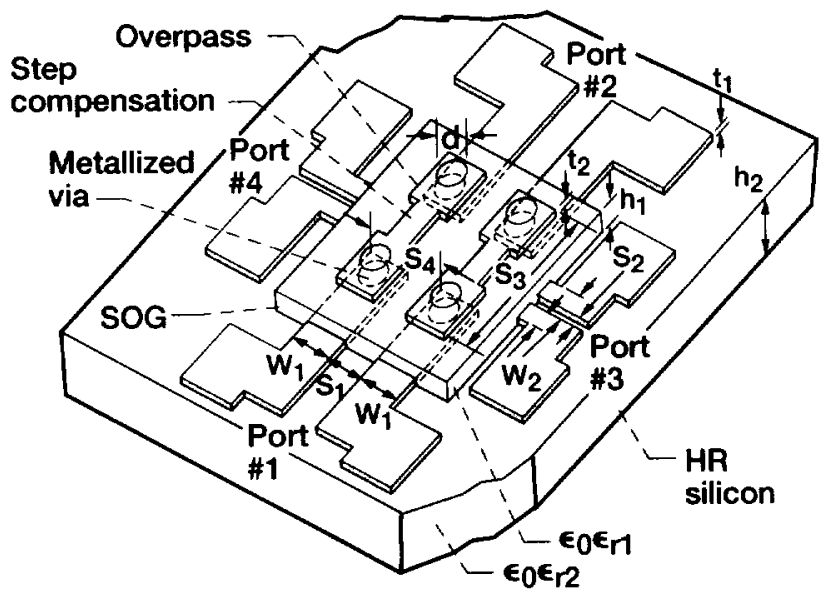

Figure 1.-Geometry of CPS overpass with crossover $W_{1}=W_{2}=W=54 \mu m S_{1}=S_{2}=S=4 \mu \mathrm{m}, d=45 \mu \mathrm{m}$, $S_{3}=328 \mu \mathrm{m}, S_{4}=58 \mu \mathrm{m}$.

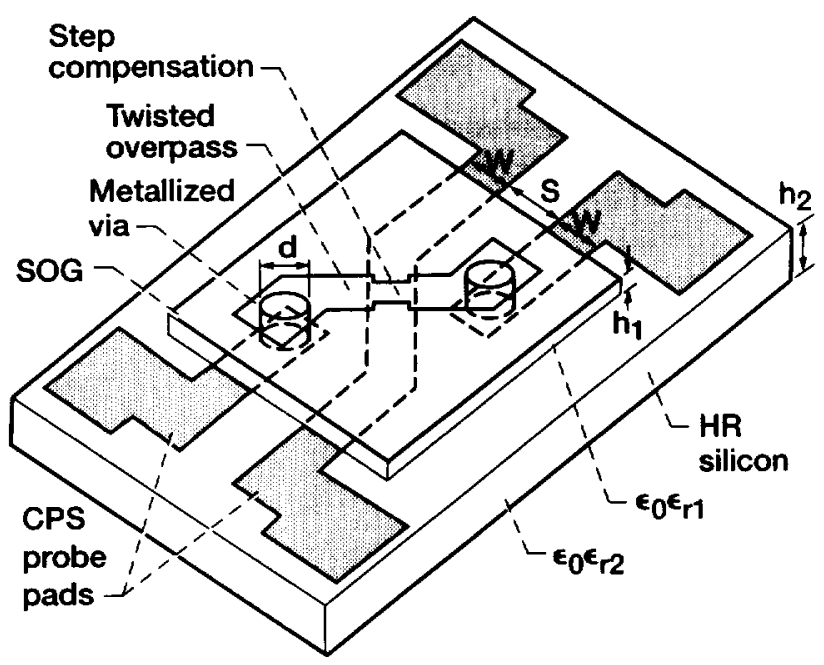

Figure 2.-CPS vertical interconnect with $180^{\circ}$ phase shift $W=54 \mu \mathrm{m}, S=4 \mu \mathrm{m}$.

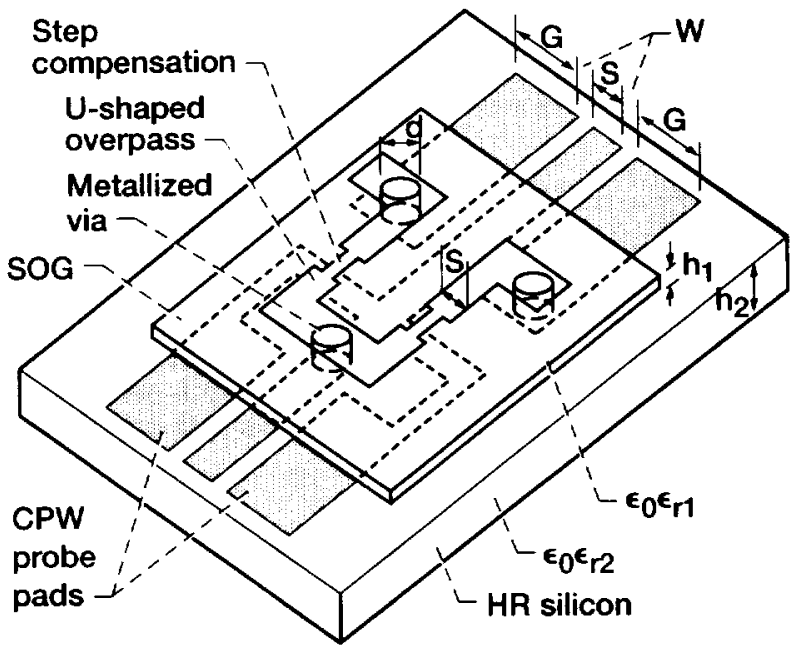

Figure 3.-CPW vertical interconnect with $180^{\circ}$ phase shift $S=54 \mu \mathrm{m}, W=34 \mu \mathrm{m}, \mathrm{G}=239 \mu \mathrm{m}$.

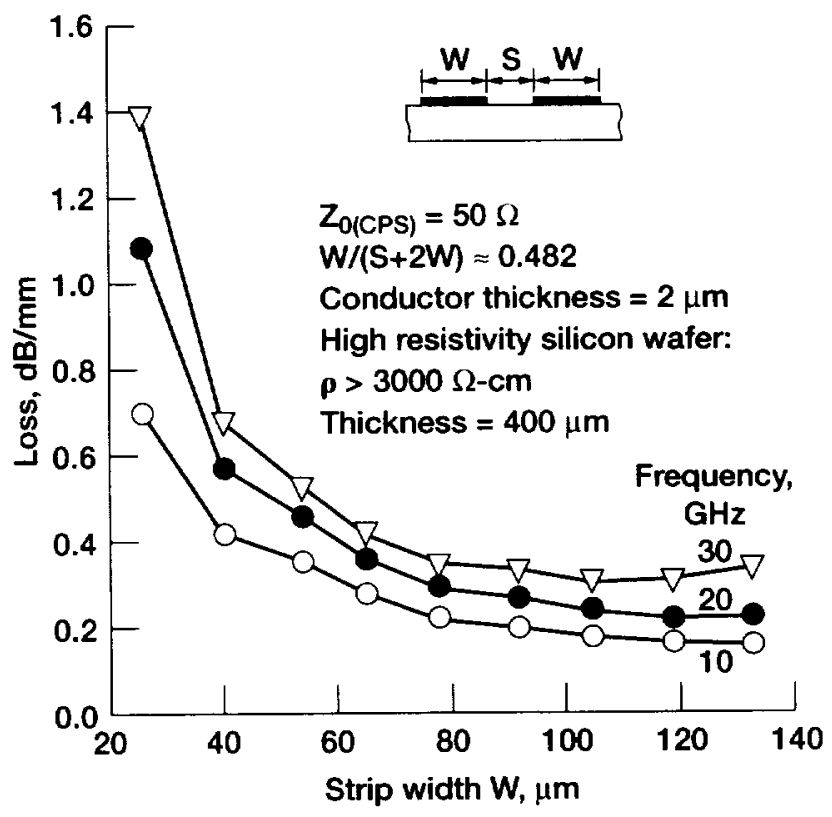

Figure 4.-Measured CPS loss versus strip width. 


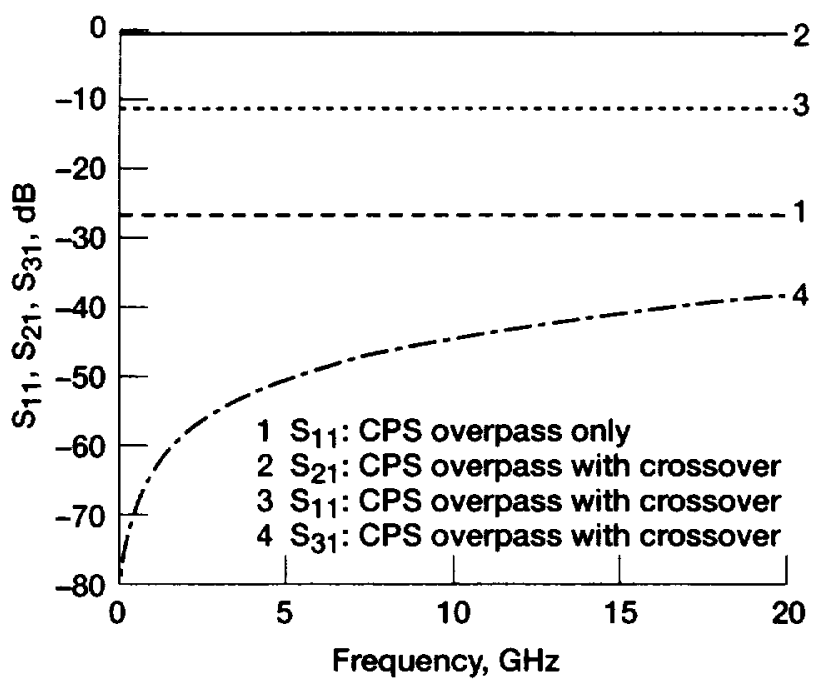

Figure 5.-Computed S-parameters for CPS vertically interconnected overpass with crossover.

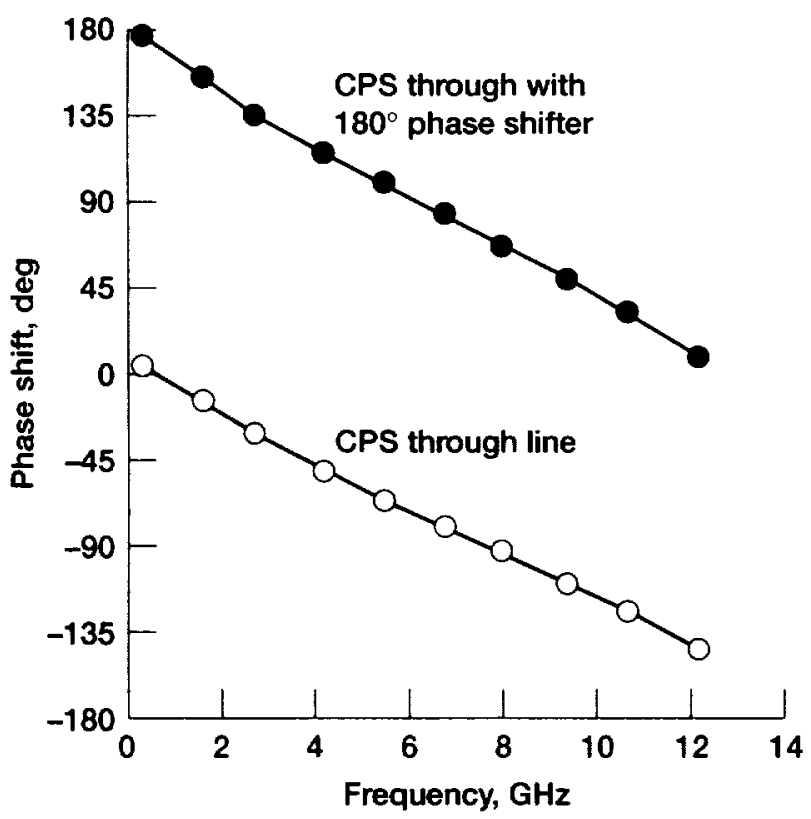

Figure 6.-Measured phase shift versus frequency $\mathrm{h}_{2}=254 \mu \mathrm{m}, \epsilon_{\mathrm{r} 2}=10.5, \mathrm{~W}=254 \mu \mathrm{m}, \mathrm{S}=75 \mu \mathrm{m}$.

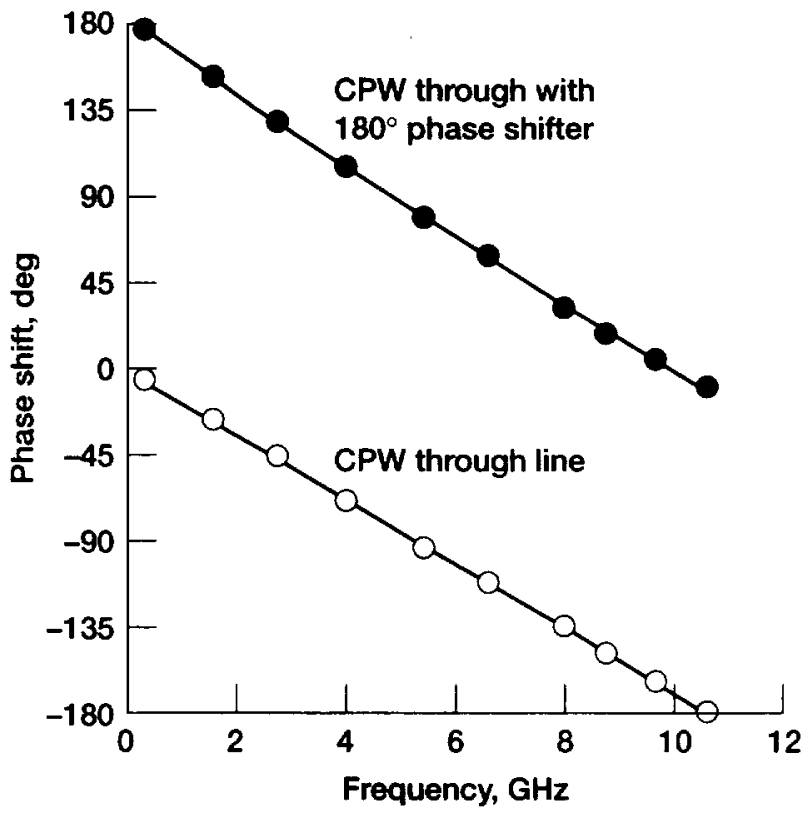

Figure 7.-Measured phase shift versus frequency $\mathrm{h}_{2}=254 \mu \mathrm{m}, \epsilon_{\mathrm{r} 2}=10.5, \mathrm{~S}=165 \mu \mathrm{m}, \mathrm{W}=75 \mu \mathrm{m}$ $\mathrm{G}=457 \mu \mathrm{m}$. 

Public reporting burden for this collection of information is estimated to average 1 hour per response, including the time for reviewing instructions. searching existing data sources, gathering and maintaining the data needed. and completing and reviewing the collection of information. Send comments regarding this burden estimate or any other aspect of this collection of intormation, including suggestions for reducing this burden, to Washington Headquarters Services, Directorate for Information Operations and Reports, 1215 Jefferson Davis Highway. Sulte 1204. Arlinglon. VA 22202-4302, and to the Office of Management and Budget, Paperwork Reduction Project (0704-0188), Washing10n, DC 20503.
1. AGENCY USE ONLY (Leave blank)
2. REPORT DATE
March 1999
3. REPORT TYPE AND DATES COVERED
Technical Memorandum

4. TITLE AND SUBTITLE 5. FUNDING NUMBERS

Novel Three-Dimensional Vertical Interconnect Technology for Microwave and

RF Applications

6. AUTHOR(S)

WU-632-50-5B-(0)

Kavita Goverdhanam, Rainee N. Simons, and Linda P.B. Katehi

7. PERFORMING ORGANIZATION NAME(S) AND ADDRESS(ES)

National Aeronautics and Space Administration

John H. Glenn Research Center at Lewis Field

Cleveland, Ohio 44135-3191

8. PERFORMING ORGANIZATION

REPORT NUMBER

E-11573

9. SPONSORINGMONITORING AGENCY NAME(S) AND ADDRESS(ES)

10. SPONSORING/MONITORING AGENCY REPORT NUMBER

National Aeronautics and Space Administration

Washington, DC 20546-0001

NASA TM-1999-209043

\section{SUPPLEMENTARY NOTES}

Prepared for the MTT-S International Microwave Symposium sponsored by the Institute of Electrical and Electronics Engineers, Anaheim, California, June 13-19, 1999. Kavita Goverdhanam and Linda P.B. Katehi, University of Michigan, Radiation Laboratory, EECS Department, Ann Arbor, Michigan 48109-2122; Rainee N. Simons, Dynacs, Inc., 2001 Aerospace Parkway, Brook Park. Ohio 44142 (work funded by NASA Contract NAS3-98008). Responsible person, Rainee N. Simons, organization code 5640, (216) 433-3462.

12a. DISTRIBUTION/AVAILABILITY STATEMENT 12b. DISTRIBUTION CODE

Unclassified - Unlimited

Subject Category: 33

Distribution: Nonstandard

This publication is available from the NASA Center for AeroSpace Information. (301) 621-0390.

13. ABSTRACT (Maximum 200 words)

In this paper, novel 3D interconnects suitable for applications in microwave and RF integrated circuit technology have been presented. The interconnect fabrication process and design details are presented. In addition, measured and numerically modeled results of the performance of the interconnects have been shown. The results indicate that the proposed technology has tremendous potential applications in integrated circuit technology.

14. SUBJECT TERMS

Coplanar stripline: Vertical interconnect; Spin-on-glass; High resistivity silicon; Antennas

17. SECURITY CLASSIFICATION OF REPORT

Unclassified

NSN 7540-01-280-5500
18. SECURITY CLASSIFICATION OF THIS PAGE

Unclassified
19. SECURITY CLASSIFICATION OF ABSTRACT

Unclassified
15. NUMBER OF PAGES

10

16. PRICE CODE $\mathrm{A} 02$

20. LIMITATION OF ABSTRACT 